\title{
Exploring an HR Ecosystem: A Glimpse through Ten Gs
}

\author{
Ajantha S. Dharmasiri \\ Director, Postgraduate Institute of Management, \\ University of Sri Jayewardenepura, Sri Lanka \\ director@pim.lk
}

\begin{abstract}
This concept paper is an attempt to present an HR ecosystem through a multi-layer framework involving ground, group, general and global levels. An ecosystem is briefly presented as a community of living organisms, drawing from its biological origins. It highlights a Seven $G$ framework of HRM in the institutional context and moves beyond to industry and international perspectives in capturing three more Gs. Thus, the resulting ten Gs can be stated as Goal, Get, Give, Grow, Glue, Glow, Guard, Grapple, Grip and Gratify. Each of the above $G$ is briefly discussed with associated challenges in the Sri Lankan context with possible recommendations for improvements. With a simplified approach, significant strategic imperatives are envisaged in order to reap the benefits of a vibrant HR ecosystem.
\end{abstract}

Keywords: HR Ecosystem, 10 G framework, HR Management

\section{Introduction}

Ecosystems are so essential for the nature. They provide basis for survival and sustainability. This concept paper explores the nature and features of an ecosystem in relation to Human Resource Management (HRM). It also attempts to link Human Resources (HR) ecosystem for competitiveness, in four levels, namely ground, group, general and global. Expanding the seven G framework of HRM (Dharmasiri, 2015) in an institutional context to cover industrial to international perspectives, a novel ten $\mathrm{G}$ approach is proposed. 


\section{Ecosystems in a Nutshell}

An ecosystem can be described in multiple ways. The typical biology textbooks call it a community of living organisms. It can further be described as a group of interconnected elements, formed by the interaction of a community of organisms with their environment (Grumbine, 1994). It appears that the business world has borrowed the term from biology and adapted it to suit the business needs. As such, it can be views as any system or network of interconnecting and interacting parts.

The essential feature of an ecosystem is the lively interactions among the elements. It is a dynamic set of interrelationships that create value. An ecosystem can be influenced by internal as well as external factors. The scope and the space of an ecosystem may vary. In fact, the entire planet has been identified as a mega ecosystem.

\section{HRM in Focus}

It is worthwhile recalling the way we defined HRM for Sri Lanka as an initiative of the Institute of Personnel Management (IPM), Sri Lanka. Based on the brainstorming conducted as a team and feedback obtained from professionals and professors, the following definition emerged.

"A strategic and integrated approach in acquisition, development and engagement of talent, using relevant tools, with proper policies, practices and processes in creating a conducive climate towards achieving organizational excellence and societal wellbeing (Dharmasiri et al, 2014)".

What we meant by strategic is working towards achieving overall goals and specific objectives of the organization. It is essentially aligning with the broad organizational priorities. It highlights the strategic significance of HRM and the holistic role it should play.

Talent refers to three Cs going in line with Ulrich et al (2009), namely, competence, commitment and contribution. He in fact puts it as an equation.

\section{Talent $=$ Competence $\mathbf{X}$ Commitment $\mathbf{X}$ Contribution}


The multiplication sign in the above equation symbolizes the collaborator and combine nature of the three vital aspects. Competence essentially refers to the knowledge (head), commitment refers to action (hands) and contribution is related values (heart).

What we do with talent occupy a significant segment of our definition. Acquisition refers to hiring (recruitment, selection and placement). Engagement means a range of aspects such as involvement, attachment and extra effort. There is a reference to the term, relevant tools in our definition. What we meant was to incorporate testing methods, assessment techniques etc. which should be linked to the organizational requirements (Armstrong, 2012).

We consciously included the term Conducive Climate in our HRM definition. This means a supportive environment within organization. HR has a critical role to play in creating such a climate. Climate refers to those aspects of the environment that are consciously perceived by organizational members (Rao, 1990). Perception is essentially an understanding based on the information obtained by senses such as eyes and ears. Hence, climate is something people see, hear and feel. That is why we see a difference when we enter a hospital, police station or a restaurant. In summary, climate is what we see and feel when we enter an organization, whereas, culture is something much deeper as bedrock.

The end result of all HR endavours, the way we see, is having twin aspects, Organizational Excellence and Societal Well-being. What we mean by organizational excellence is its overall performance with continuous improvement. It, obviously, include financial results, customer satisfaction, process efficiency and people development, the four perspectives of a typical balanced scorecard.

HR professionals cannot function in isolation ignoring the social realities. This is more relevant to a developing country like ours, where issues such as poverty, unemployment and ethnic tensions cannot be ignored. That's why we included Societal Well-being as a key outcome of HRM. It highlights the need to support people outside the organization and protecting the environment as well. 


\section{HR Ecosystem through Ten Gs}

It is indeed fascinating to see how HRM operates at various levels within an institution as well as outside an institution. I propose an HR ecosystem as a combination of ten Gs, namely, Goal, Get, Give, Grow, Glue, Glow, Guard, Grapple, Grip and Gratify. They are related mainly to four levels, from micro to macro. I would identify them as Ground, Group, General and Global. Figure 01 illustrates such multiple facets in multiple levels.

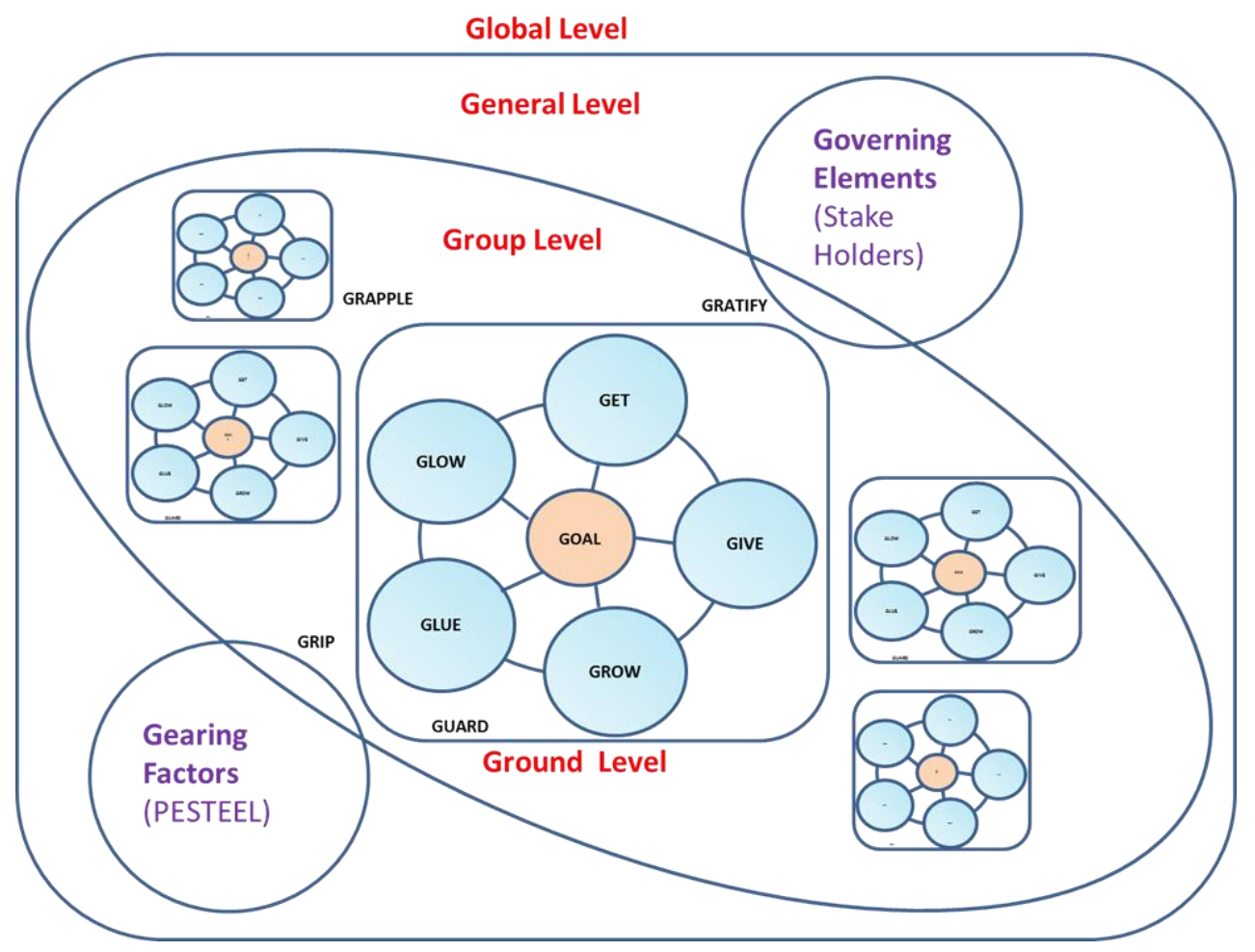

Figure 01: HR Ecosystem through ten Gs

Source: Author's Concept

Let's go through the details of the ten Gs depicted in figure 01 with examples. 


\subsection{Ground Level}

I propose this as the institutional or organizational context. It could be private or public. The first seven Gs are very much in existence here.

\subsubsection{Goal}

This occupies the centre stage in setting the direction of the entire organization. It revolves around the strategic intent, comprising vision, mission or aspiration whatever the terminology may be. Aligning the grooming of people with goals of the organization should be the right approach (Thomson et al, 2014). There are numerous occasions where people are unclear about their top goals and priorities.

Strategic Human Resource Management (SHRM) appears prominently in this context. SHRM is an approach that defines how an organization's goals will be achieved through people by means of HR strategies and integrated HR policies and practices.

\subsubsection{Get}

This is all about getting the right people in. The hiring challenge looms large for organization in diverse environments, mainly owing to a talent gap. I would call it R-R gap, the gap between required talent and raw talent. The market is abundant with raw talent, especially with school leavers. Are they geared to a demanding job in a target-driven environment? Sadly, the answer is no. We teach complex subject matter but not how to gain confidence. Job-orientation in the academic courses has been recognized as important only of late (Dharmasiri et al, 2008).

In practical terms, updated job descriptions and job specifications should be available for each position and these should be used in the selection process (Baur et al, 2014). Also, selecting the appropriate test in predicting future performance on the specific job is of importance. Managers should be trained on effective hiring, with special emphasis on interviewing skills.

\subsubsection{Grow}

This refers to the need to build people. Training and development go hand in hand. The simple difference is that the former is for current and the latter 
is for future. In essence, training is to do something. Development is to be someone. Both are intertwined in such a way that training leads to development.

Choices in training and development are captured here. Identification of training and development needs is of utmost importance in this regard. Having clarity on programme participants, presenters, designers, coverage, delivery methods and expected behavioural changes are some of the vital components associated.

A growing emphasis on training effectiveness with proper mechanisms to measure is seen in the Sri Lankan private sector. Use of Kirkpatrick model to assess training effectiveness at different levels is one such approach (Kirkpatrik \& Kirkpatrik, 1994). Return on Training Investment (ROTI) has slowly become a critical factor in the local scenario as well, in justifying the monetary allocation for training and development.

\subsubsection{Give}

"If you give peanuts, you get monkeys", goes the old saying. What you give to the person who came in by way of reward and recognition is of utmost importance in the context of competition. Your competitor can grab our best talent by "giving" more.

One may observe that some Sri Lankan organizations have well-structured reward and recognition schemes. What is needed more could be strengthening of the behavioural aspects, such as verbal appreciation of exceptional performance (Ranasinghe \& Dharmasiri, 2013).

\subsubsection{Glue}

I would associate the feature "binding" with glue. This refers to the range of choices in retaining talent. Having developed the knowledge and skills of high performers of any organization, seeing them leaving is the last thing an organization would like to see. The multi-faceted phenomena of employee engagement needs to be dealt with appropriate strategies (Shuck \& Karen, 2011). 
Finding out why talented people leave and taking appropriate actions to arrest the outflow should be high in the HR agenda. Offering of a variety of financial and non-financial rewards to stay has also needs to be strengthened.

Encouraging evidence can be found in many leading organizations in Sri Lanka. Yet, the reality remains that, when overseas opportunities are galore with unmatchable financial offers, employees tend to seek better prospects. As I have seen in many organizations, effectively engaging the employees with a clear purpose can be a sure-cure in arresting the rot.

\subsubsection{Glow}

This is the subtlest of all. It can appear in several forms. As one such form, choices in promoting the employees can be captured. When a career ladder is available for them to climb, and when the organization is genuinely providing the support and encouragement, chances of them contributing better in a more committed manner is high. Establishing criteria for new jobs, allowing volunteers to take up challenging tasks, evaluating candidates' potential, supporting of new job holders are some of the key actions in this regard. The broad aspects of performance management fall into this arena (Beatty et al, 2003).

In another form, encouraging the employees to unleash their potential is also a way of allowing them to "glow". Creating an environment where employees feel free to experiment, resulting in innovative products and services is a right step in this direction. Global examples such as $3 \mathrm{M}$ and Google have made this a sure fire approach in making people glow.

\subsubsection{Guard}

Guarding is all about the employee protection through a proper policy framework. It may include controls as well as clearance for creative action. A widely shared and willfully practiced set of corporate values also falls into this perspective. A weak guarding may result in employees having uncertainty and ambiguity with regard to their direction, resulting in lower involvement and contribution. 
The above seven Gs are interrelated and in existence in institutions. Let's move one step further. When many such institutions in an industry have seven Gs, there is much greater prospects for HRM to prosper.

\subsection{Group Level}

I use the term "Group" to identify many institutions in an industry. Several apparel manufacturers having seven Gs of HRM in the apparel industry is such an example. The eighth G, Grapple is required here.

\subsubsection{Grapple}

It is the reality of competition among various institutions to grab the best talent. It also highlights the way to handle possible conflicts or collaborations between different institutions with regard to HRM (Conner \& Ulrich, 1997). Among the competing organizations, how HRM practices can be shared and supported is worth exploring. In essence, grapple refers to the challenges of facing competition among the firms and how HRM should respond to such challenges.

In the diagram of HR Ecosystem, several institutions having seven Gs of HRM are represented with eighth $\mathrm{G}$ as an institutional HRM response to the industry. This in fact can be further extended to more than one industry as well.

\subsection{General Level}

This is where all industries with many institutions meet. It is essentially the broad national level where country-wide HRM policies and practices become significant. This is where twin influences occur with regard to industries and thereby the institutions within. I would like to call them gearing factors and governing elements.

\subsection{Gearing Factors}

These are the typical PESTEEL factors that gear or influence the steering of an industry or the institutions within. PESTEEL stand for political, economic, social, technical, environmental, ethical and legal factors. They affect an industry in general and an institution in specific (Porter, 1996). 
What is the implication to HRM? It is a case of having a grip on the gearing factors in making HRM policies. I propose this aspect as the ninth G; Grip.

\subsubsection{Grip}

In essence, it is the collective and committed HRM response to the gearing factors. Let's say a policy decision of allowing knowledge workers from a neighbouring country is taken. There is a need for HR professionals to discuss, decide and do the needful in such an event. That is to take a firm "grip" in responding to the influencing factor. It is a significant step in staying competitive as a nation.

Apart from the gearing factors, governing forces need our attention.

\subsection{Governing Elements}

These are the stakeholders having diverse expectations. They include government, labour unions, HR professional bodies, HR research units etc. What is required from HRM is the tenth G, which is to "gratify".

\subsubsection{Gratify}

This essentially refers to stakeholder satisfaction. HRM has a macro role here. HR professionals have to connect, cooperate and collaborate with multiple institutions, communities and organizations at national level (Ulrich \& Brockbank, 2005). These moves provide the key drivers for being more competitive as a nation.

Having discussed ground, group and general levels what is left is the global level.

\subsection{Global Level}

This is where national competitiveness matters most. For us to be more competitive as a nation at global level, HRM should produce global talent from Sri Lanka. HR professionals have a critical role in ensuring seven Gs at ground level, eighth $\mathrm{G}$ at group level and the remaining Gs at general level. The current indications such as the Global Competitiveness Index reveal a significant area for improvement in this respect. It is the 
culmination of all Gs that HRM has to offer in order for the country to be globally more competitive.

\section{Conclusion}

What we have attempted to do is to have a glimpse of the HR ecosystem through a ten $G$ approach. Each $G$ is critical in ensuring the contribution of HRM for competitiveness at all levels. The role HR professionals have to play is getting increasingly important with inherit ant complex challenges. That is why HR professionals need confidence and competence in order to climb the "uphill task".

\section{References}

Armstrong, M. (2012), Armstrong's Handbook of Human Resource Practice, London: Kogan Page.

Baur, John E, Buckley, M. R, Bagdasarov, Z, .Dharmasiri, A. S. (2014), “A Historical Approach to Realistic Job Previews: An Exploration into Their Origins, Evolution, and Recommendations for the Future", Journal of Management History, 20 (2): 200 - 210.

Beatty, R. W., Huselid, M. A. and Schneier, C. E. (2003) "New HR metrics: Scoring on the business scorecard", Organizational Dynamics, 32(2):107-121.

Dharmasiri, A.S. (2015), HRM for Managers: A Learning Guide, Colombo: Postgraduate Institute of Management.

Dharmasiri, A.S., Kumarasinghe, J. \& Perera, S. (2014), "Defining HRM for Sri Lanka”, HRM Perspectives Journal, 3: 236 -245.

Grumbine, R. Edward (1994). "What is Ecosystem Management?" Conservation Biology. 8 (1): 27-38.

Kirkpatrick, D.L. \& Kirkpatrick, J.D. (1994). Evaluating Training Programs, New York: Berrett-Koehler Publishers.

Porter E, M. (1996). "What is strategy?", Harvard Business Review, NovDec. 
Kelaniya Journal of Human Resource Management

Volume 10-Number 01-January 2015 \& Number 02-July 2015

Ranasinghe, S. \& Dharmasiri, A. S. (2013), HR Challenge: Dynamics of Value Creation and Competitiveness through People, Colombo: Institute of Personnel Management.

Rao, T. V. (1990). The HRD Missionary: Role and Function of HRD Managers and HRD Departments, New Delhi: Oxford and IBH Publishing.

Shuck, B. \& Wollard, K. K. (2011). "Antecedents to Employee Engagement: A Structured Review of the Literature". Advances in Developing Human Resources, 13 (4): 429-446.

Thompson, A. A., Peteref, M. A., Gamble, J. E., Strickland, A. J. \& Jain, A.K. (2014). Crafting and Executing Strategy; Concepts and Cases. (19 $9^{\text {th }}$ ed.). New Delhi: McGraw Hill.

Ulrich, D. \& Brockbank, Y. (2005). The HR Value Proposition, Boston: Harvard Business School Press.

Ulrich, D., Allen, J., Brockbank, W., Younger, J. \& Nyman, M. (2009), HR Transformation: Building Human Resources from the Outside In, New York: RBL.

Ulrich, D., Younger, J., Brockbank, W. \& Nyman, M. (2012), HR from the Outside In, New York: McGraw-Hill. 